\title{
Velocity increase in the uppermost oceanic crust of subducting Philippine Sea plate beneath the Kanto region due to dehydration inferred from high-frequency trapped $P$ waves
}

\author{
Shunsuke Takemura ${ }^{1 *}$, Kazuo Yoshimoto ${ }^{1}$ and Takashi Tonegawa ${ }^{2}$
}

\begin{abstract}
To investigate the detailed structural properties of the oceanic crust of subducting oceanic plate, we analyzed high-frequency ( 1 to $16 \mathrm{~Hz}$ ) trapped $P$ waves during earthquakes that occurred near the oceanic crust of the Philippine Sea plate. The distinct trapped $P$ waves observed by the dense seismic network of the Kanto-Tokai region, Japan, did not show any apparent peak delay and frequency-dependent dispersion. These observations suggested that the oceanic crust around the source depths was characterized by a homogeneous velocity structure, rather than an inhomogeneous multiple-layered structure. This interpretation was examined by finite difference method simulations of seismic wave propagation using possible velocity structure models. The simulations demonstrated that a uniform velocity oceanic crust of the subducting Philippine Sea plate, which may result from the velocity increase in this layer at 30 to $40 \mathrm{~km}$ depth due to metamorphic-dehydration reactions, effectively trapped seismic energy as a short-distance waveguide and developed distinct pulse-like trapped $P$ waves.
\end{abstract}

Keywords: Subduction; Philippine Sea plate; Oceanic crust; Trapped waves; Dehydration

\section{Background}

Many geophysical phenomena in subduction zones, such as the generation of arc volcanism and the occurrence of intraslab earthquakes, are considered to be related to fluid transportation into the mantle by subducting oceanic plates (e.g., Tatsumi 1989; Kirby et al. 1996; Magee and Zoback 1993). Previous studies suggested that the hydrated oceanic crust, which is the uppermost part of a subducting plate, plays an important role in fluid transportation into the mantle (e.g., Iwamori and Zhao 2000; Kawakatsu and Watada 2007). Since hydrous minerals in this layer become unstable with the increasing temperature and pressure due to the subduction, dehydration reactions in the oceanic crust are expected to occur accompanied by the release of fluids to the surrounding structures, resulting in the transformation to an anhydrous

\footnotetext{
* Correspondence: shunsuke@yokohama-cu.ac.jp

'Department of Material System Science, Graduate School of Nanobioscience, Yokohama City University, 22-2, Seto, Kanazawa-ku, Yokohama 236-0027, Japan Full list of author information is available at the end of the article
}

eclogitic oceanic crust (e.g., Hacker et al. 2003; Kawakatsu and Watada 2007; Tsuji et al. 2008).

Since hydrous minerals have a lower seismic velocity than anhydrous ones, a subducting oceanic crust at depths where hydrous minerals are stable is characterized by a low-velocity layer compared to the surrounding structures, such as the mantle wedge and the oceanic mantle (e.g., Matsubara et al. 2005; Kawakatsu and Watada 2007; Nakajima et al. 2009). The seismic waves are effectively trapped in this low-velocity layer, and consequently, the trapped seismic energy is often identified as distinct later arrivals during intraslab earthquakes in the subduction zone (e.g., Fukao et al. 1983; Hori et al. 1985; Hori 1990; Abers et al. 2003; Martin and Rietbrock 2006; Miyoshi et al. 2012; Shiina et al. 2014). Trapped $P$ and $S$ waves appear several seconds after the arrival of the relatively weak direct body waves. Previous studies reported that trapped $P$ and $S$ waves are only well observed for a particular geometry between source and receivers for earthquakes occurring in the oceanic crust and that their maximum amplitudes are 5 to 10 times 
larger than those of the first arrivals (e.g., Fukao et al. 1983; Miyoshi et al. 2012). Furthermore, their apparent velocities are approximately 7 and $4 \mathrm{~km} / \mathrm{s}$, respectively, corresponding well with the $P$ - and $S$-wave velocities in the oceanic crust. Thus, trapped seismic waves are considered as guided waves propagating along the lowvelocity oceanic crust. This indicates that the study of trapped seismic waves potentially allows us to investigate the seismological structure relevant to a subducting oceanic crust. Using observations of travel times and dispersion features of trapped waves, previous studies have revealed properties of the oceanic crust, such as its geometry, thickness, seismicity, and depth of eclogitization (e.g., Fukao et al. 1983; Hori 1990; Abers et al. 2003; Miyoshi et al. 2012). However, the detailed features of trapped waves and heterogeneous structure in the oceanic crust still remain uncertain, especially for smallscale velocity heterogeneities that strongly affect highfrequency seismic wave propagation.

By analyzing the seismicity and the seismic later arrivals in the Kanto-Tokai region, Japan (Figure 1a), Hori (1990) pointed out that the low-velocity layer at the top of the Philippine Sea plate could be detected down to a depth of $60 \mathrm{~km}$. In this study, we assume that this layer is the subducting oceanic crust of the Philippine Sea plate. Meanwhile, using travel-time tomography for $P$ and $S$ waves in the Kanto region, Kamiya and Kobayashi (2000) and Matsubara et al. (2005) detected the lowvelocity anomaly (LVA) of the mantle wedge at depths of 30 to $40 \mathrm{~km}$ and interpreted it as the dehydration of the hydrated crust of the Philippine Sea plate. Although the spatial resolution of travel-time tomography is insufficient to investigate the detailed velocity structure of the thin oceanic crust of the Philippine Sea plate, their results implied that structural changes in this layer due to dehydration are expected at these depths.

In this study, to investigate the velocity change of seismic waves in the subducting crust, we analyzed trapped $P$ waves propagating along the oceanic crust of the Philippine Sea plate beneath the Kanto-Tokai region and conducted finite difference method (FDM) simulations of seismic wave propagation using realistic velocity structure models. A large number of data derived from the dense seismic network Hi-net (Okada et al. 2004) enabled more detailed analyses of the features of highfrequency trapped $P$ waves and of the heterogeneous structure in the crust. Using FDM simulations, we were able to examine not only the travel times but also the amplitude and envelope shape of the filtered trapped $P$ waves for frequencies up to $16 \mathrm{~Hz}$. This allows the investigation of the internal velocity structure of the oceanic crust and of how trapped $P$ waves develop in this layer. Based on the comparison between the observed and simulated seismograms, we demonstrate that the $P$-wave velocity in the uppermost oceanic crust of the Philippine Sea plate increases up to approximately $7 \mathrm{~km} / \mathrm{s}$ at depths of 40 to $50 \mathrm{~km}$ in the Kanto region. We also show how the trapped $P$ waves are affected by small-scale velocity heterogeneities in the crust and mantle.

\section{Methods}

Data and analysis method for the observed seismograms

The trapped seismic waves are only well observed for a particular geometry between sources and receivers in the case of earthquakes that occurred in the oceanic crust of oceanic plate (e.g., Fukao et al. 1983; Hori et al. 1985; Miyoshi et al. 2012). In the Kanto-Tokai region, Hori $(1990,2006)$ reported that seismograms of local earthquakes, occurring at depths of 50 to $60 \mathrm{~km}$ in the oceanic crust of the Philippine Sea plate beneath the Kanto region, were characterized by prominent trapped $P$ and $S$ waves. These phases, clearly observed southwest of the seismic sources (shaded area in Figure 1a) which is perpendicular to the direction of subduction, were interpreted as trapped $P$ and $S$ waves propagating along the low-velocity oceanic crust of the Philippine Sea plate. Figure $1 \mathrm{~b}$ shows the vertical velocity seismograms recorded at the Hi-net stations (Figure 1a), located southwest from the source, during event 5 (black focal sphere in Figure 1a). Distinct later arrivals, several seconds after the weak $P$ arrivals, were clearly observed at distances of 90 to $150 \mathrm{~km}$ (Figure $1 \mathrm{~b}$ ). The apparent velocity of this phase was approximately $7 \mathrm{~km} / \mathrm{s}$, roughly corresponding to the $P$-wave velocity in the lower oceanic crust. Similar distinct later arrivals were observed during other events (e.g., events 6 and 7) of similar epicenter locations but different source depths (Figure 1c,d). The observed distinct later phases were interpreted as trapped $P$ waves propagating along the oceanic crust of the Philippine Sea plate. To obtain better insights into the structure of the subducting oceanic crust, we analyzed the detailed features of the trapped $P$ waves during these events. The trapped seismic waves were not clearly observed in other areas because the stations were located in the back-arc side or the Kanto Basin. To reveal the propagation features of the trapped $P$ waves and detailed seismic velocity structure inside this layer, we further analyzed the velocity seismograms recorded at the Hi-net stations. Hi-net is a high-sensitivity seismogram network operated by the National Research Institute for Earth Science and Disaster Prevention, Japan (Okada et al. 2004). Each Hi-net station consists of three-component velocity-type seismometers with a natural frequency of $1 \mathrm{~Hz}$ installed in a borehole. Each velocity seismogram was corrected for the frequency response of the Hi-net borehole sensors (Maeda et al. 2011). Based on the observations by Hori (1990, 2006), we selected seven earthquakes occurring at depths of 50 to $60 \mathrm{~km}$ near the oceanic crust of 
a)

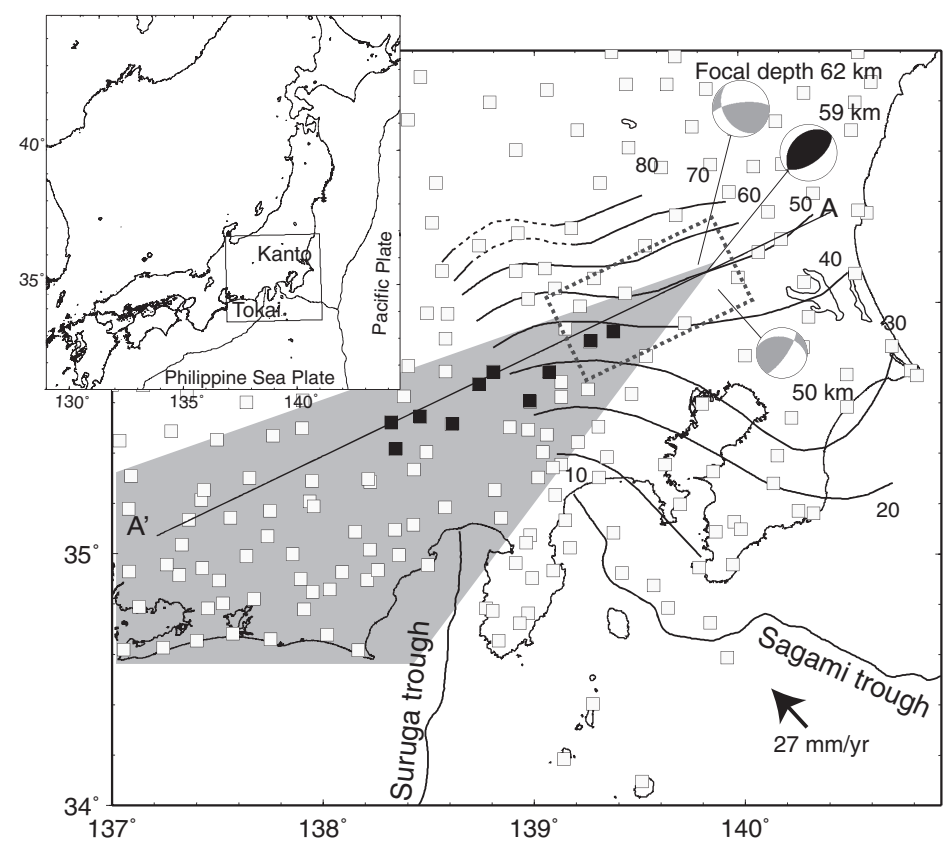

b) Ev. 5

Depth $59 \mathrm{~km}$

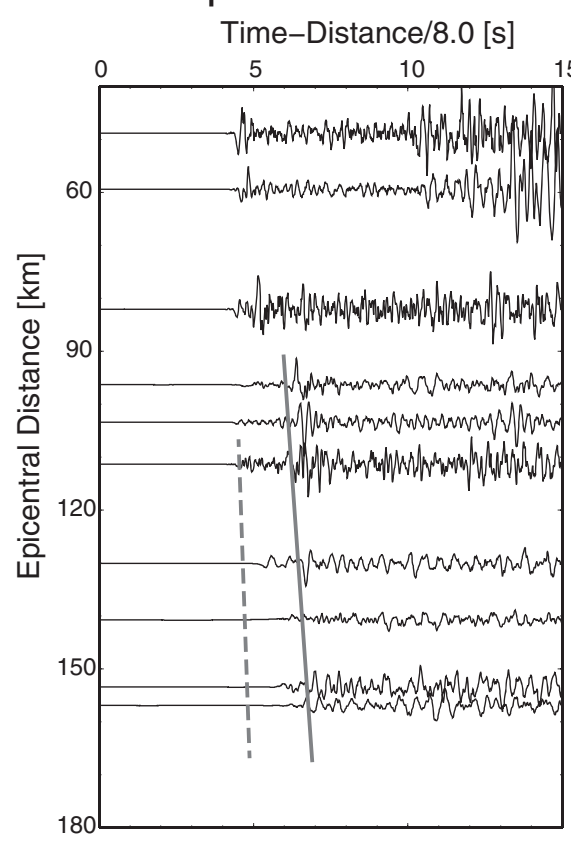

c) Ev. 6

Depth $62 \mathrm{~km}$

Time-Distance/8.0 [s]

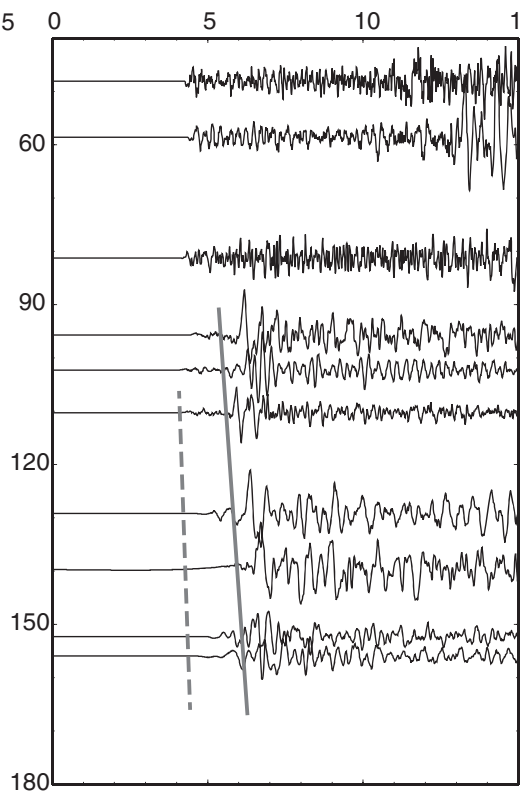

d) Ev. 7

Depth $50 \mathrm{~km}$

Time-Distance/8.0 [s]

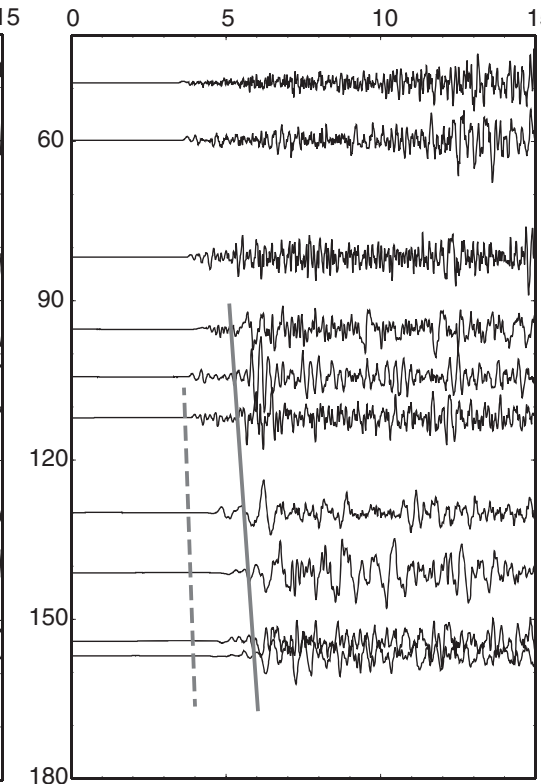

Figure 1 Map of the Kanto-Tokai region and vertical velocity seismograms. (a) Distribution of the Hi-net (Okada et al. 2004). (b) Vertical velocity seismograms recorded at the Hi-net stations (black filled squares) during event 5 (black focal sphere). (c, d) Vertical velocity seismograms during two other events. The isodepth lines of the upper surface of the Philippine Sea plate (Hirose et al. 2008a) are shown for $10 \mathrm{~km}$ intervals in (a). Arrow in (a) shows the direction of the Philippine Sea plate motion (Seno et al. 1993). The trapped signals are clearly observed in the region inside shaded area (Hori 1990, 2006). Line A-A' represents the area of the 2D simulation in the $x$ direction and the region inside the dotted rectangle in (a) is the area of the 3D simulation in the horizontal direction. The amplitude of each trace was normalized to its maximum amplitude. The gray dashed and solid lines in each trace are the onsets of the $P$ and trapped $P$ waves, respectively. 
the Philippine Sea plate beneath the Kanto region (Figure 1). The analyzed earthquakes are shown in Table 1. The source parameters for each event were referred from the centroid moment tensor (CMT) solutions of the F-net (Fukuyama et al. 1998; Okada et al. 2004).

To obtain better insights into the detailed velocity structure of the oceanic crust of the Philippine Sea plate, we applied a bandpass filter with passed frequencies of 1 to 2,2 to 4,4 to 8 , and 8 to $16 \mathrm{~Hz}$ to the corrected velocity waveforms of vertical component (Figures 2 and 3). To investigate the high-frequency seismic wave propagation in the oceanic crust of the Philippine Sea plate, we analyzed the filtered seismograms and their envelope shapes. The amplitude of the filtered vertical seismograms was normalized by its maximum amplitude for a 15-s time window, starting $5 \mathrm{~s}$ prior to the arrival time of the $P$ wave. The averaged root mean square (RMS) envelope of the vertical component at each station was calculated by stacking the 15-s envelopes of the normalized seismograms observed for all earthquakes (Figure 4). The application of the stacking procedure weakens the multi-path effects and enhances the averaged path effects from source to receiver.

\section{FDM simulation of the seismic wave propagation}

To model the observed features of the high-frequency trapped $P$ waves obtained from the waveform analysis, we conducted two-dimensional (2D) FDM simulations of the high-frequency seismic wave propagation along profile A-A' (Figure 1a), perpendicular to the direction of subduction. We mainly conducted 2D FDM simulations to examine the various possible structure models. The 2D model covered an area of $327.68 \times 102.40 \mathrm{~km}^{2}$, in the horizontal and vertical directions, respectively, discretized by a small grid interval of $0.02 \mathrm{~km}$. The propagation of the seismic waves was calculated by solving the equation of motion in a $2 \mathrm{D}$ elastic medium based on the staggered-grid FDM technique with fourth- and second-order accuracies in space and time (e.g., Levander 1988; Graves 1996). To effectively conduct the relatively large-scale 2D simulation, we used a parallel FDM simulation code based on a domain partitioning procedure using large number processors through the message passing interface (MPI) (e.g., Furumura and Chen 2004). We applied suitable boundary conditions for the solid-to-air interface at the free surface in the FDM simulation, as developed by Okamoto and Takenaka (2005).

The background velocity structure was constructed using the Japan Integrated Velocity Structure Model (JIVSM) proposed by Koketsu et al. (2008), which is one of the latest and most widely used structure models in Japan. This structure model includes a two-layered lowvelocity crustal structure at the top of the Philippine Sea plate: two layers, hereafter referred to as 'upper oceanic crust' and 'lower oceanic crust', have almost constant thicknesses of approximately 3 and $4 \mathrm{~km}$, respectively. The $3-\mathrm{km}$ thickness of the uppermost layer $\left(V_{\mathrm{P}}=4.8\right.$ to $5.2 \mathrm{~km} / \mathrm{s}$ ) is consistent with estimations by seismic reflection surveying near the Sagami Trough (Kimura et al. 2009). The almost constant $7-\mathrm{km}$ thickness of the oceanic crust may be supported by receiver function analysis and seismic activities (Hori 2006; Kimura et al. 2006; Kato et al. 2010). The thickness of the oceanic mantle of the Philippine Sea plate was assumed to be approximately $50 \mathrm{~km}$ (e.g., Kumar and Kawakatsu 2011). Hereafter, we call this heterogeneous velocity structure model constructed here the 'original JIVSM' (Figure 5a). The detailed parameters of the physical properties for each layer are shown in Table 2.

Each parameter was obtained from Koketsu et al. (2008). $V_{\mathrm{P}}, V_{\mathrm{S}}$ and $\rho$ are the $P$-wave and $S$-wave velocities and density, respectively. $Q_{\mathrm{P}}$ and $Q_{\mathrm{S}}$ are the quality factors for $P$ and $S$ waves, respectively.

For the 2D FDM simulations, we used the CMT solution derived from the F-net of event 5 in Table 1, which occurred at a depth of $59 \mathrm{~km}$ on 18 May 2012. The source depth was slightly adjusted to set the source in the oceanic crust for the assumed velocity structure model, since for earthquakes occurring outside the this layer, large-amplitude trapped seismic waves are not observed (e.g., Fukao et al. 1983; Hori 1990; Miyoshi et al. 2012). The $P$ and $S V$ waves with a source time function represented by a single-cycle Kupper wavelet (Mavroeidis and Papageorgiou 2003) with a dominant frequency of

Table 1 Characteristics of the earthquakes used in the analysis

\begin{tabular}{llllll}
\hline Number & Origin time (local time) & Longitude & Latitude & Depth (km) & Mw \\
\hline 1 & 4 April 2008 19:01 & 139.828 & 36.120 & 56.0 & 4.8 \\
2 & 2 April 2011 16:55 & 139.962 & 36.207 & 56.0 & 5.8 \\
3 & 26 April 2011 21:12 & 139.976 & 36.086 & 3.0 & 59.0 \\
4 & 11 February 2012 10:26 & 139.789 & 36.088 & 59.0 & 4.8 \\
5 & 18 May 2012 17:18 & 139.841 & 36.136 & 3.0 & 4.8 \\
6 & 16 July 2012 04:31 & 139.817 & 36.152 & 30.0 & 4.3 \\
7 & 1 February 2013 01:04 & 139.893 & 36.056 & & 5.0 \\
\hline
\end{tabular}




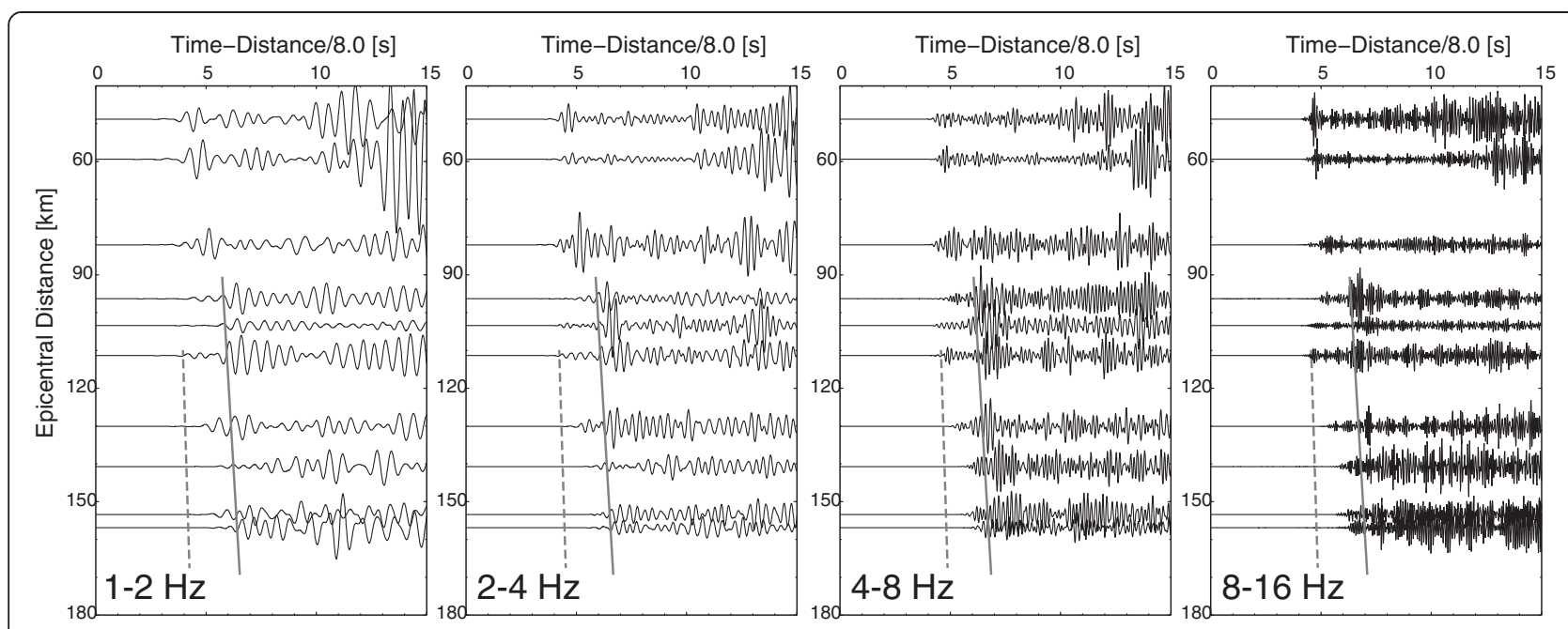

Figure 2 Filtered velocity seismograms of the vertical component during event $\mathbf{5}$. The amplitude of each trace was normalized to its maximum amplitude. The gray dashed and solid lines in each trace are the onsets of the $P$ and trapped $P$ waves, respectively.

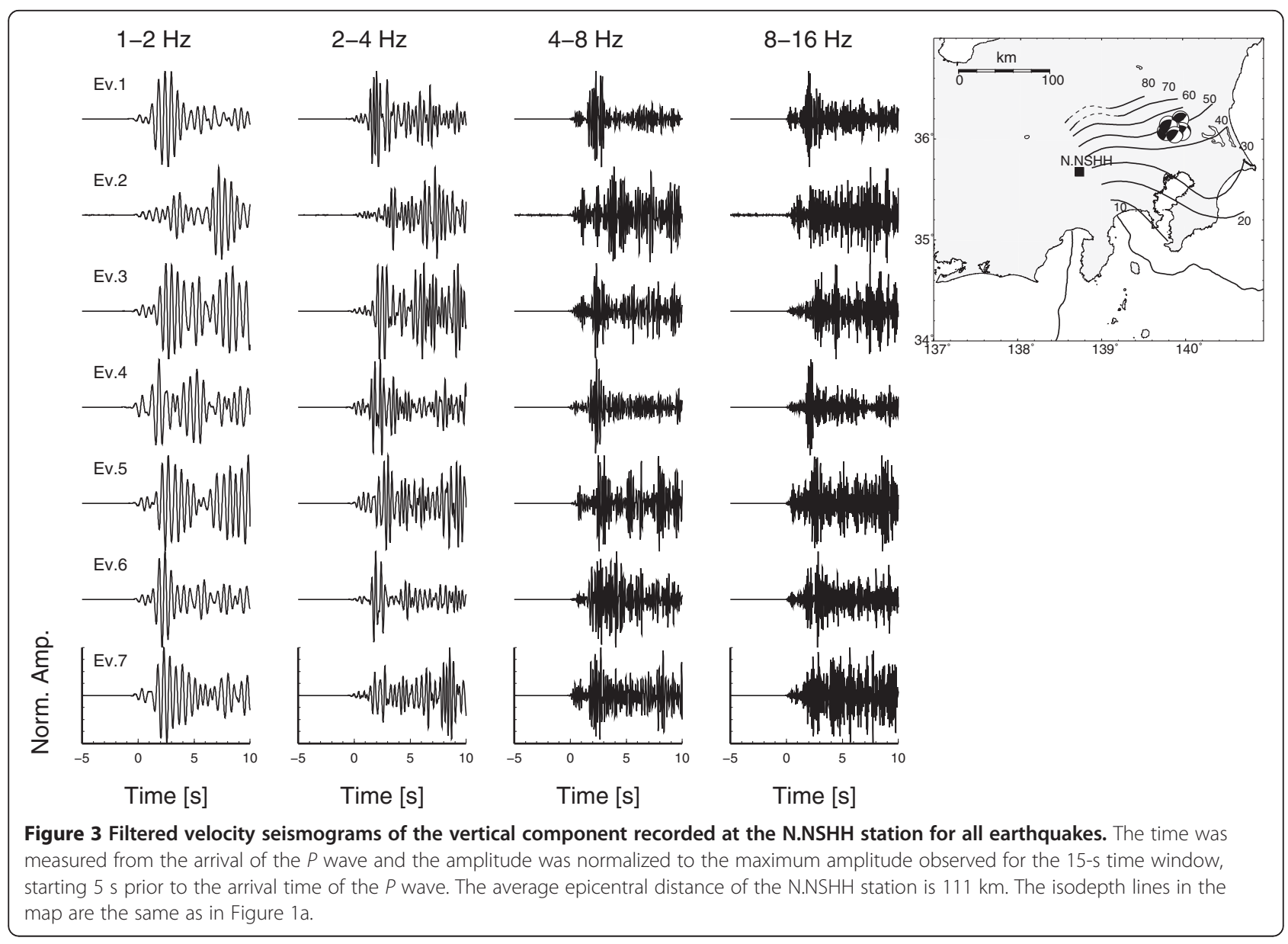



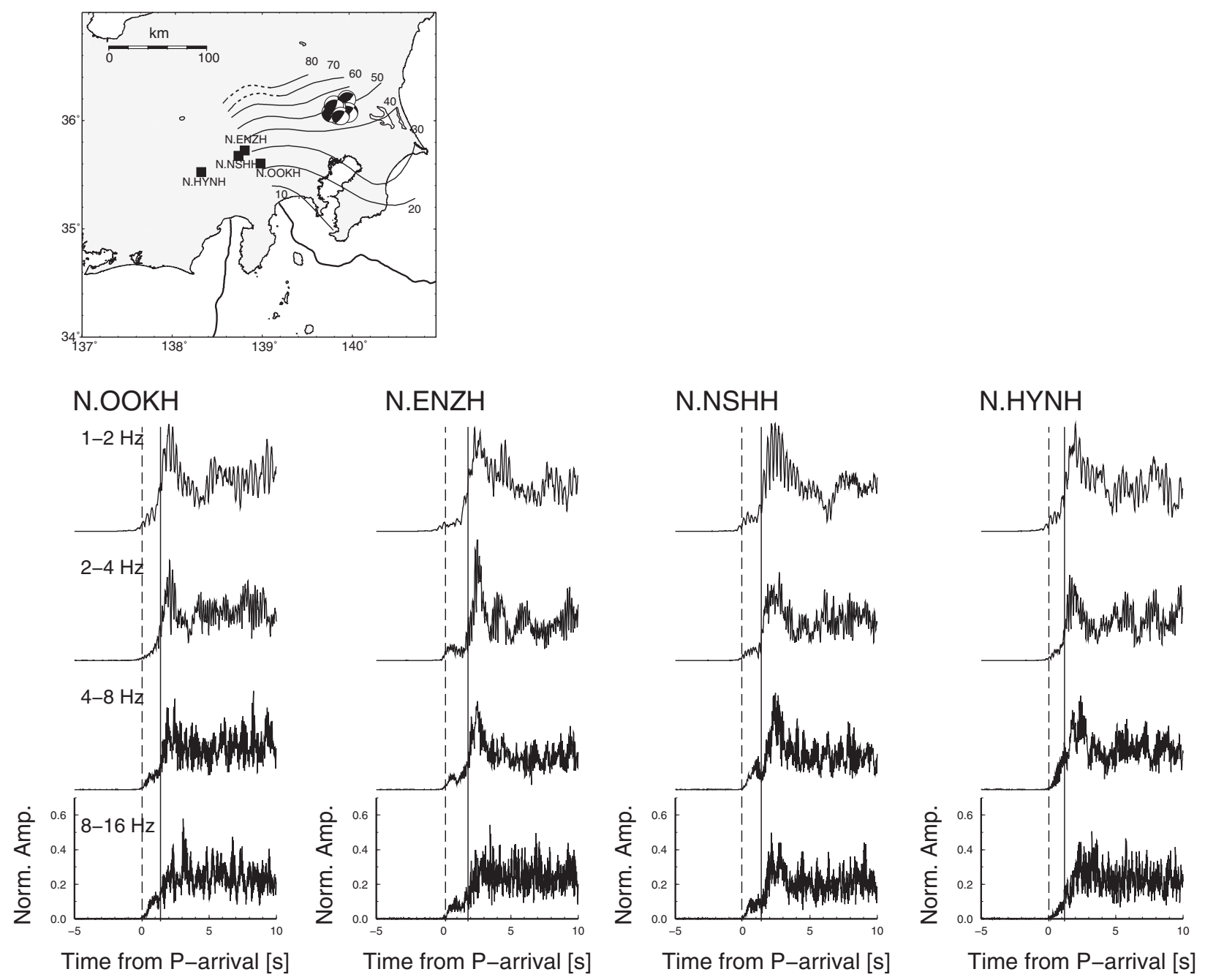

Figure 4 Normalized RMS envelopes of the filtered vertical velocity seismograms. The time was measured from the arrival of the $P$ wave. The isodepth lines in the map are the same as in Figure 1a. The averaged epicentral distances of stations N.OOKH, N.ENZH, N.NSHH, and N.HYNH are $96,103,111$, and $155 \mathrm{~km}$, respectively.

approximately $6 \mathrm{~Hz}$ were radiated from the assumed source.

Along profile A-A' (Figure 1a), the LVA of the mantle wedge was detected just above the oceanic crust of the Philippine Sea plate at depths of 30 to $40 \mathrm{~km}$ by tomography studies (e.g., Matsubara et al. 2005). Thus, we introduced the LVA in the simulation model along profile A-A', where the seismic $P$ - and $S$-wave velocities were reduced by $10 \%$ compared with the original JIVSM. The location of the LVA was referred from tomography results from Matsubara et al. (2008), corresponding to the lower crust and mantle in the JIVSM. In addition, we modified the original JIVSM by introducing the velocity increase for $P_{-}$and $S$-wave velocities in the upper oceanic crust of the Philippine Sea plate at depths below the LVA, to reproduce the observed pulse-like trapped $P$ waves. Two constructed models (A1 and A2) had different strength of velocity increases in the lower oceanic crust. We also introduced the small-scale velocity heterogeneities in the crust, mantle, and oceanic plate to examine the effects of seismic scattering on the trapped $P$ waves. The parameters of small-scale velocity heterogeneities were referred from the Table four of Takemura and Yoshimoto (2014).

The 3D effects, especially the 3D geometry of the subducting oceanic crust, were not taken into account in the 2D simulations. Thus, it is difficult to compare directly $2 \mathrm{D}$ simulation results with the observations. To confirm the effect of a 3D geometry of the subducting plate on the propagation of the trapped $P$ waves, we also conducted 3D FDM simulations of seismic wave propagation in 3D heterogeneous structure models and examined the limitations of our 2D simulations. Since it is difficult to conduct highly accurate full 3D simulations 


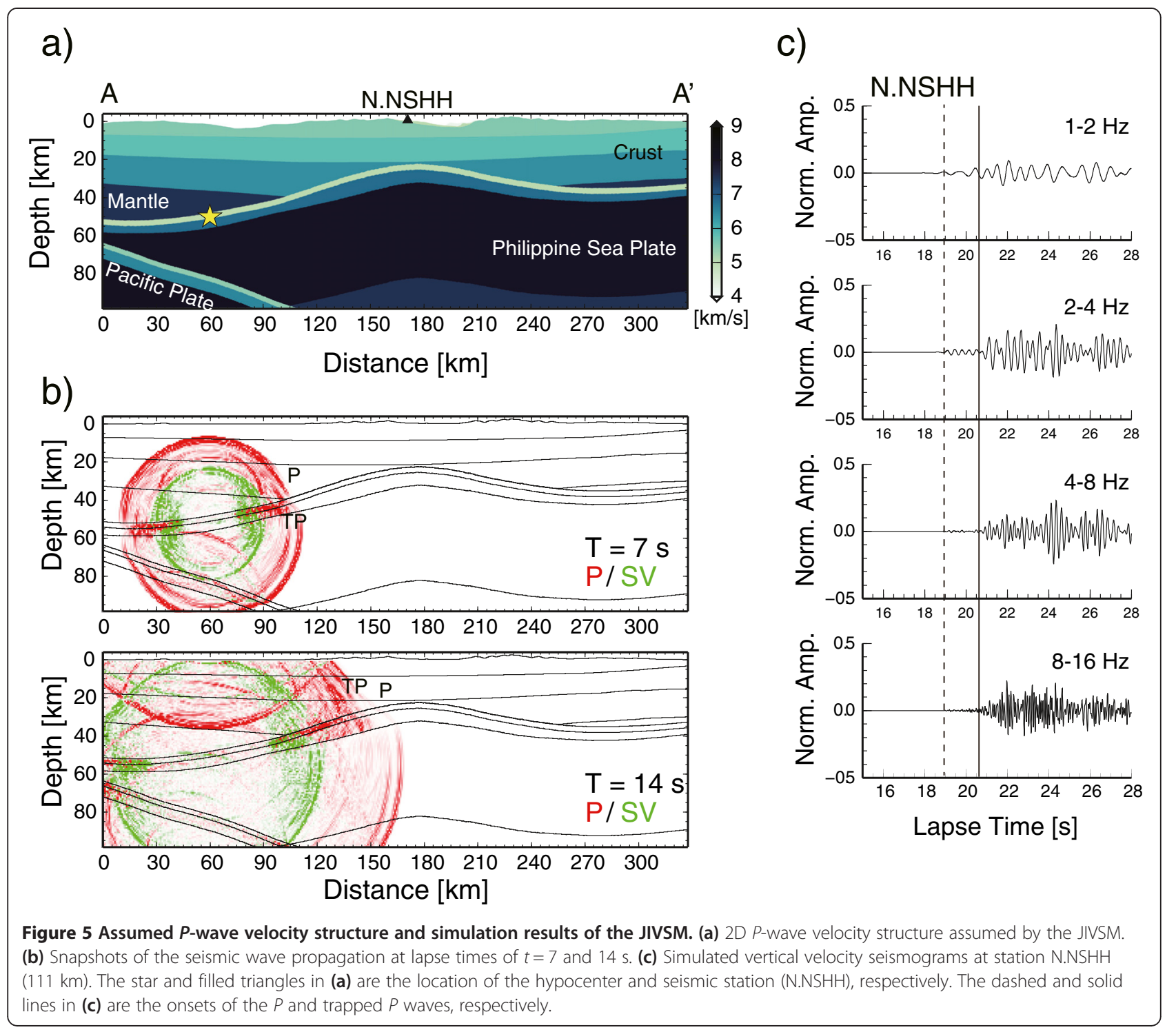

for frequencies up to $16 \mathrm{~Hz}$, our 3D simulation was localized in the region covering an area of $81.0 \times 40.5 \times$ $45.0 \mathrm{~km}^{3}$ around seismic source (dotted rectangle in Figure 1a) discretized by a uniform grid size of $0.03 \mathrm{~km}$, to focus on the propagation of the trapped $P$ waves along the oceanic crust. The 3D simulation provided $P$ wave seismograms for a virtual station in the lower crust located where the trapped energy was released from the oceanic crust. The effect of the 3D structure on the released trapped waves might be weak because of a relatively simple structure of the crust.

\section{Results and discussion}

\section{Waveform analysis of the observed high-frequency} trapped $P$ waves

To understand how trapped $P$ waves of different frequency components propagate along the oceanic crust, we first demonstrate their frequency dependency. As shown in Figure 2, trapped $P$ waves were clearly observed for all frequency bands at epicentral distances of 90 to $150 \mathrm{~km}$, whereas the long-duration and incoherent coda waves were excited by seismic wave scattering in the crust and mantle. This indicates that the trapped energy from $P$ waves might not be strongly affected by the scattering loss due to small-scale heterogeneities in the crust.

Despite the differences in source mechanisms and hypocenter locations, the trapped $P$ waves were clearly observed in the filtered vertical velocity seismograms recorded at the N.NSHH station for all earthquakes used in the analysis (Figure 3). In general, as the frequency increases, the seismic wave scattering due to small-scale velocity heterogeneities along the propagation path becomes more dominant and distorted seismograms characterized 
Table $2 \boldsymbol{P}$ - and $\boldsymbol{S}$-wave velocities, densities, and anelastic attenuation of the JIVSM

\begin{tabular}{|c|c|c|c|c|c|}
\hline & $V_{\mathrm{P}}[\mathrm{km} / \mathrm{s}]$ & $V_{\mathrm{S}}[\mathrm{km} / \mathrm{s}]$ & $\rho\left[\mathrm{g} / \mathrm{cm}^{3}\right]$ & $Q_{P}$ & $Q_{\mathrm{s}}$ \\
\hline \multicolumn{6}{|l|}{ Layer } \\
\hline Basement & 5.5 & 3.2 & 2.65 & 680 & 400 \\
\hline Upper crust & 5.8 & 3.4 & 2.70 & 680 & 400 \\
\hline Lower crust & 6.4 & 3.8 & 2.80 & 680 & 400 \\
\hline Upper mantle & 7.5 & 4.5 & 3.20 & 850 & 500 \\
\hline \multicolumn{6}{|l|}{ Philippine Sea plate } \\
\hline Upper oceanic crust & 5.0 & 2.9 & 2.40 & 340 & 200 \\
\hline Lower oceanic crust & 6.8 & 4.0 & 2.90 & 510 & 300 \\
\hline Oceanic mantle & 8.0 & 4.7 & 3.20 & 850 & 500 \\
\hline \multicolumn{6}{|l|}{ Pacific Plate } \\
\hline Oceanic crust layer 2 & 5.4 & 2.8 & 2.6 & 340 & 200 \\
\hline Oceanic crust layer 3 & 6.5 & 3.5 & 2.8 & 510 & 300 \\
\hline Oceanic mantle & 8.1 & 4.6 & 3.4 & 850 & 500 \\
\hline
\end{tabular}

by frequency-dependent pulse broadening and peak delay are observed (Sato et al. 2012; Takahashi et al. 2007). However, the pulse-like trapped $P$ waves were observed irrespective of the frequency, while the seismograms became more complicated with increasing frequency. Trapped $P$ waves were observed for frequencies up to $16 \mathrm{~Hz}$ and those dominant features were not influenced by slight changes in source location and fault mechanisms.

Figure 4 shows the stacked RMS envelopes of the vertical component recorded at four $\mathrm{Hi}$-net stations with average epicentral distances of 100 to $150 \mathrm{~km}$. The trapped $P$ waves were clearly observed at all stations, showing pulse-like waveforms without significant dispersion and peak delay. The averaged amplitudes of the trapped $P$ waves were 5 to 7 times larger than those of the first arrivals. These characteristics suggest that the trapped $P$ waves might be caused by a specific velocity structure of the subducting oceanic crust, which effectively traps high-frequency $P$-wave energy.

\section{Simulations of the high-frequency trapped $P$ waves}

The observed characteristics of trapped $P$ waves suggest a hypothesis that the subducting oceanic crust might be characterized by a specific velocity structure. Our hypothesis was examined by 2D FDM simulations of seismic wave propagation using realistic velocity structure models. The simulation results of the original JIVSM (Figure 5a) are shown in Figure 5b,c. High-frequency $P$ waves propagated along the heterogeneous structure, repeating reflections and refractions at each velocity boundary (Figure $5 \mathrm{~b}$ ). The trapped $P$ waves (marked TP in Figure 5b) efficiently propagated along the lowvelocity oceanic crust and then the trapped energy was released into the crust at depths of 30 to $35 \mathrm{~km}$, where the impedance contrast between the top of the oceanic crust and the above media became smaller. This zone of energy release into the crust was located at more than $50 \mathrm{~km}$ from the source. Consequently, trapped $P$ waves were clearly observed at epicentral distances of 90 to $150 \mathrm{~km}$ as shown in the snapshots (Figure 5b). The short-distance $(<60 \mathrm{~km})$ waveguide in the oceanic crust caused the large-amplitude trapped $P$ waves after the weak direct $P$ waves as seen in the simulated seismograms (Figure 5c). However, especially for higher frequencies (4 to 8 and 8 to $16 \mathrm{~Hz}$ ), distinct trapped signals were not clearly observed and the peak arrivals were strongly

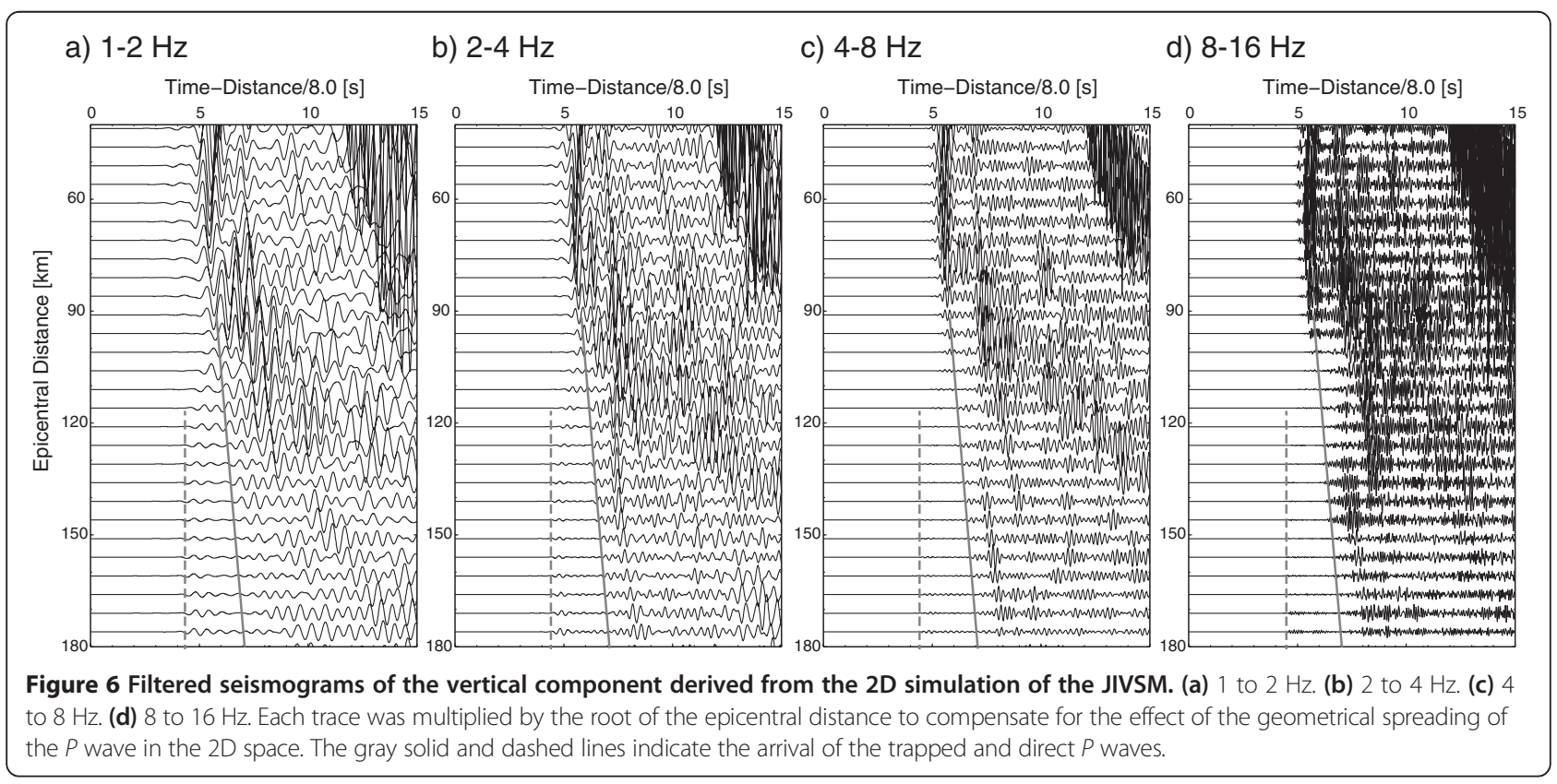


delayed, showing spindle-shaped seismograms. These discrepancies between observation and simulation were found not only for the N.NSHH station but also for distances of 90 to $150 \mathrm{~km}$ (Figure 6). Since the $P$-wave energy for frequencies of 4 to 8 and 8 to $16 \mathrm{~Hz}$ with shorter wavelengths ( 0.42 to $1.7 \mathrm{~km}$, assuming $\left.V_{\mathrm{P}}=6.8 \mathrm{~km} / \mathrm{s}\right)$ was trapped in the upper oceanic crust (3-km thickness) rather than in the lower oceanic crust or both, the simulated trapped $P$ waves were delayed and broadened, and failed to explain the observed pulse-like trapped $P$ wave.
The $2 \mathrm{D}$ simulation results of the modified models A1 and A2 (see Figure $7 \mathrm{~b}, \mathrm{c}$ ) are shown in Figure 8a,b, respectively. The blue triangles in Figure $7 b, c$ denote the LVA detected by tomography study (Figure 7a). The simulated seismograms of model A1 (left part of Figure 8a) exhibited that the trapped $P$ waves were not easily distinguished for all seismograms and their amplitudes were comparable to those of other later phases. Therefore, the modeled velocity increase in the upper oceanic crust might be insufficient to develop the pulse-like

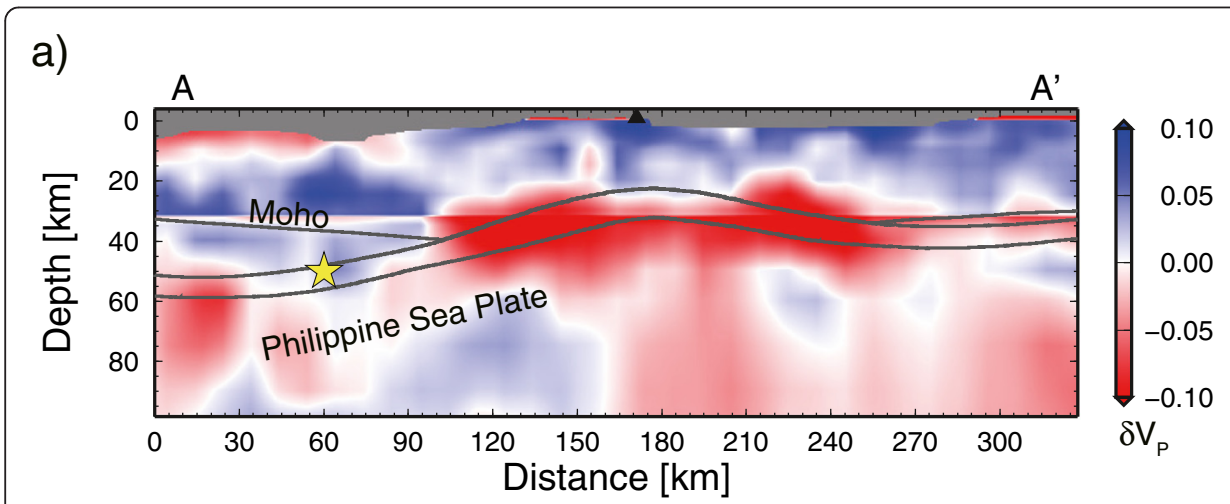

\section{b) model A1}
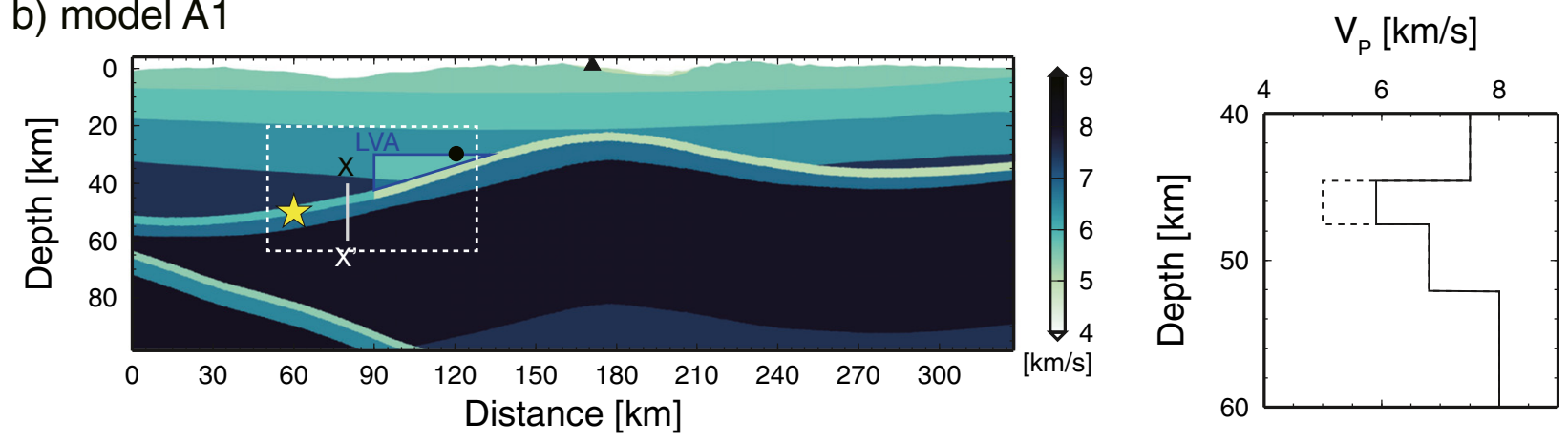

\section{c) model A2}
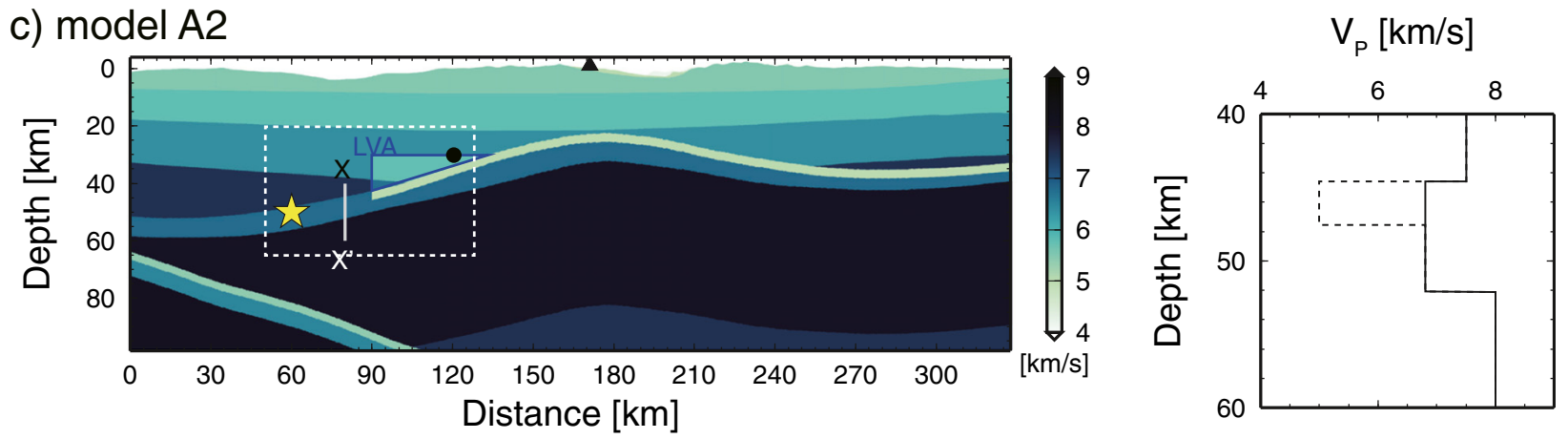

Figure $7 P$ wave velocity structure of the modified simulation models. (a) $P$ wave velocity perturbation estimated by a tomography study (Matsubara et al. 2008). (b) Model A1. (c) Model A2. Solid lines in (a) represent the Moho interface, the upper surface of Philippine Sea plate, and the oceanic Moho from the JIVSM layered structure. The depth variations in $P$ wave velocity along the vertical profile $X-X^{\prime}$ are shown on the right side of Figure $6 \mathrm{~b}, \mathrm{c}$. The solid and dashed lines represent the $P$ wave velocity structure around the oceanic crust in the modified model and in the original JIVSM, respectively. The area of the LVA at depths of 30 to $40 \mathrm{~km}$ is represented by the blue triangle. The filled triangle represents the seismic station of the 2D simulations. The dotted white rectangle and the black circle are the area and the seismic station for the 3D simulation, respectively. The yellow star is the location of the hypocenter. 


\section{a) model A1}

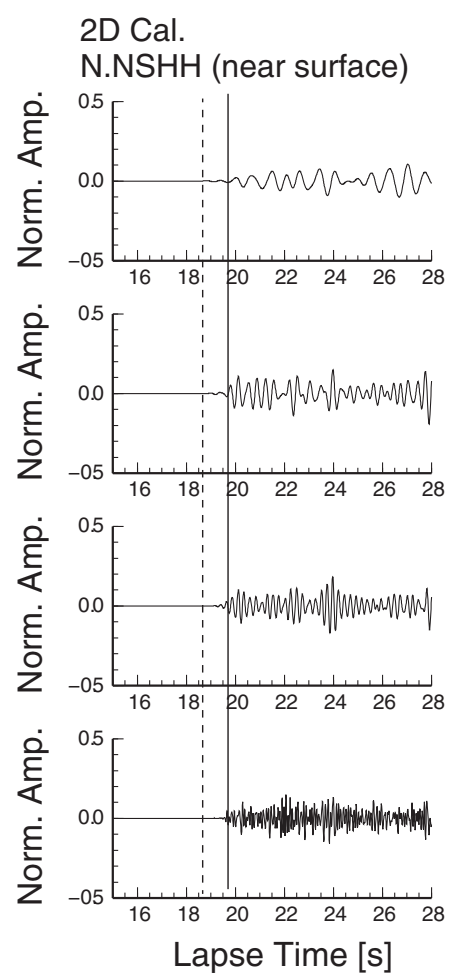

3D Cal.

at the lower crust
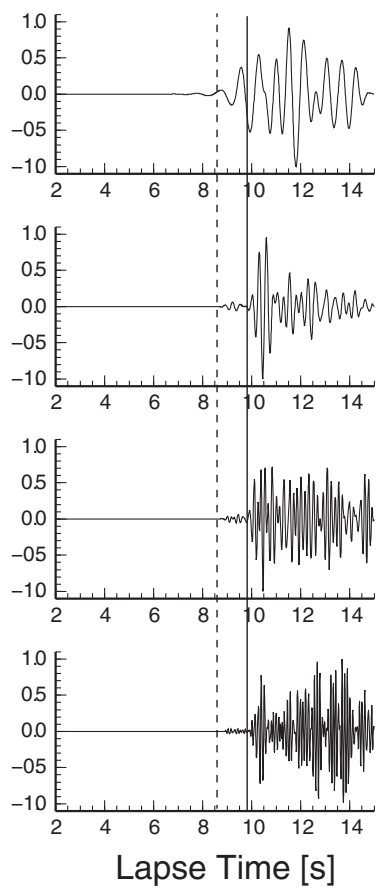

\section{b) model $\mathrm{A} 2$}

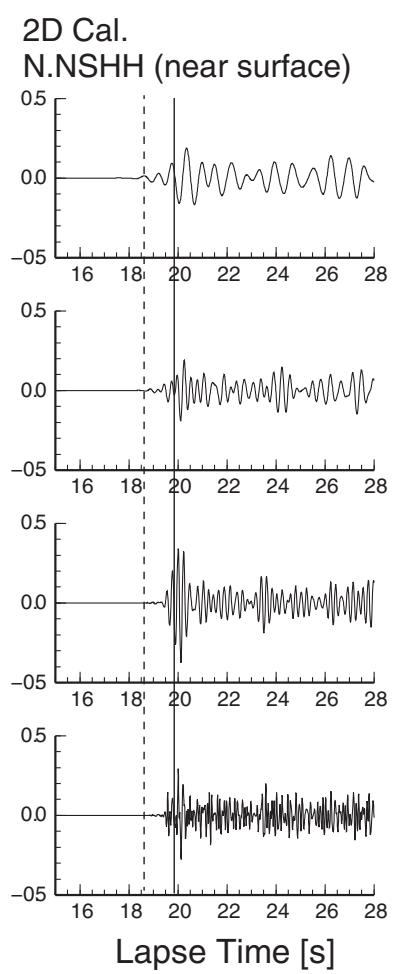

3D Cal.

at the lower crust
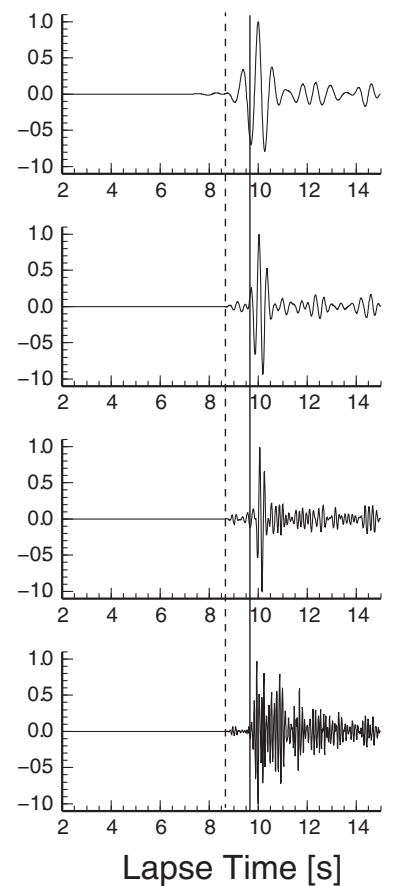

Figure 8 Simulated vertical velocity seismograms derived from the 2D and 3D simulations. (a) Model A1. (b) Model A2. The dashed and solid lines in each trace are the onsets of the $P$ and trapped $P$ waves, respectively. The location of the stations in the 2D and $3 \mathrm{D}$ models is shown in Figure $7 b, c$.

trapped $P$ waves. In contrast, in the case of model A2 (left part in Figure $8 \mathrm{~b}$ ), which assumed the same $P$-wave velocity for the upper and lower oceanic crusts around the source depths, distinct pulse-like trapped $P$ waves were significantly developed for all frequency bands. A uniform velocity oceanic crust of the Philippine Sea plate (Figure 7c) behaved as an effective short-distance waveguide and reproduced the distinct pulse-like trapped $P$ waves. We also showed the simulated waveforms derived from 3D FDM simulations (right part in Figure 8a,b) to confirm 3D effects on the propagation of trapped $P$ waves. These waveforms were observed at a virtual station in the lower crust (black circle in Figure $7 \mathrm{~b}, \mathrm{c}$ ). The comparison between the 2D and 3D simulations showed no significant difference for the very early part of the $P$ waves (Figure $8 \mathrm{a}, \mathrm{b}$ ), thereby validating our interpretation based on 2D simulations.

Figure 9 shows the simulated seismograms of vertical component from epicenter to far stations. The travel times of the direct and trapped $P$ waves were slightly different from the observations, as our simulations were conducted in a 2D space and the effect of full 3D heterogeneities between source and receiver were not taken into account. The filtered seismograms of the vertical component derived from the 2D simulation (model A2) showed the propagation of the distinct pulse-like trapped $P$ waves at longer distances (Figure 9a). We also confirmed that the LVA did not affect the propagation features of the trapped $P$ waves (Figure $9 \mathrm{~b}$ ). However, the travel times of trapped $P$ waves at a distance of 90 to $120 \mathrm{~km}$ were slightly different from the original model A2 (Figure 9a). The LVA changed the release point of the trapped energy into the crust.

In previous simulations, we did not consider the effects of seismic wave scattering due to small-scale velocity heterogeneities, which have the potential to decrease the amplitude and delay the peak arrivals of high-frequency signals. However, when small-scale velocity heterogeneities of the crust and upper mantle were introduced in model A2, the distinct trapped $P$ waves remained the same as in the observations. Figure 10a shows the averaged RMS envelopes of the vertical component derived from the $2 \mathrm{D}$ simulation results using model A2 with ten runs of stochastic random velocity heterogeneities. By introducing small-scale velocity heterogeneities, long-duration coda waves were excited after the peak arrival of the trapped $P$ 


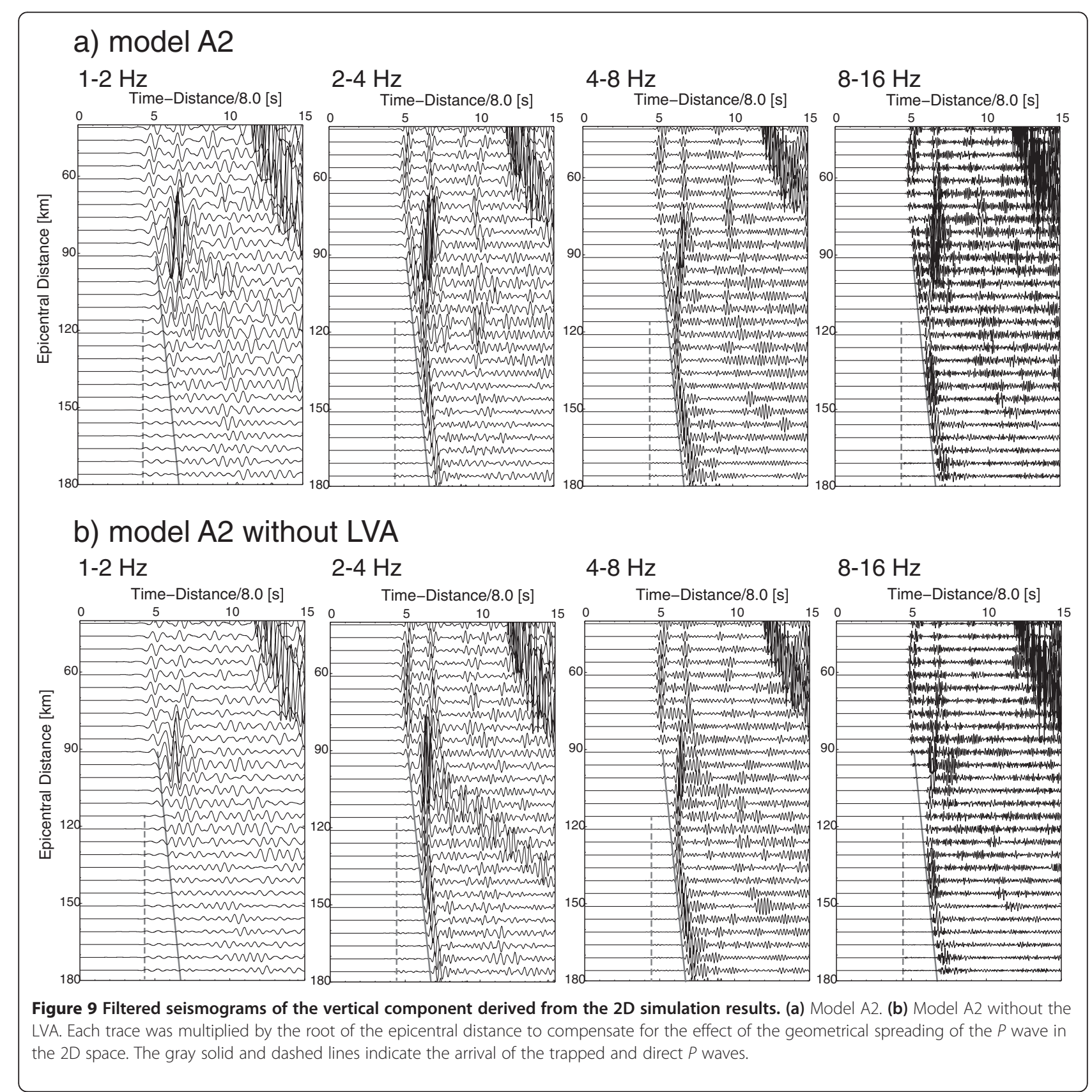

waves compared with model A2 without small-scale velocity heterogeneities (Figures $8 \mathrm{~b}$ and 9 ). However, no significant dispersion or peak delay of the trapped $P$ waves was observed as in the observed envelopes (Figure 10b). The trapping of $P$ wave energy in the oceanic crust was sufficiently strong to preserve its amplitude at longer distances in a medium with small-scale velocity heterogeneities.

\section{Dehydration reactions in the uppermost oceanic crust of the Philippine Sea plate}

According to the 2D and $3 \mathrm{D}$ simulations, the distinct pulse-like trapped $P$ waves were caused by the short- distance waveguide due to a uniform velocity structure of the oceanic crust the Philippine Sea plate at depths below $40 \mathrm{~km}$. We may suggest that the dehydration of upper oceanic crust at depths of 30 to $40 \mathrm{~km}$ contributes to the formation of this uniform velocity structure. Seismic velocities and thickness of the uniform oceanic crust around source region well correspond to those estimated by tomography and seismic activities studies (Hori 2006; Kimura et al. 2006; Hirose et al. 2008a, b). In Tokai and southwestern Japan, using travel-time tomography, Hirose et al. (2008b) and Kato et al. (2010, 2014) detected similar velocity changes in the oceanic crust of 


\section{a) 2D simulation}

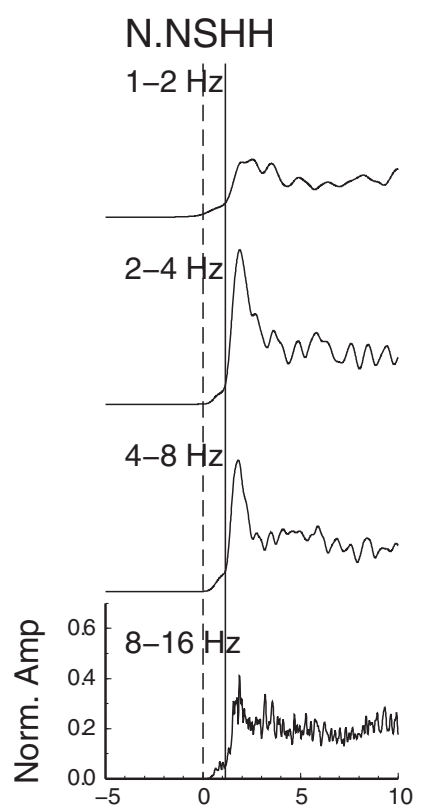

Time from P-arrival [s]

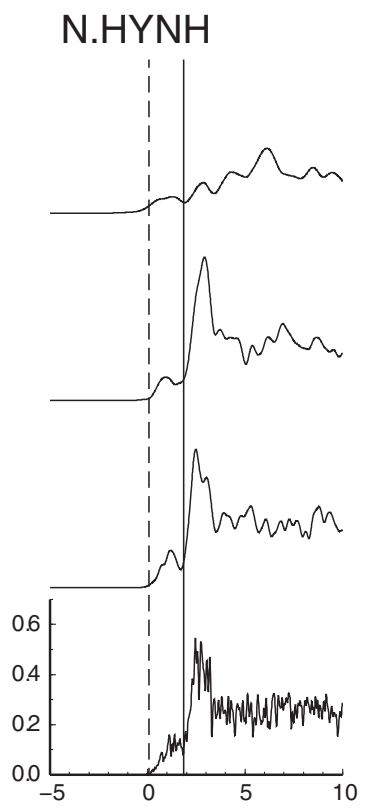

Time from P-arrival [s] b) Observation

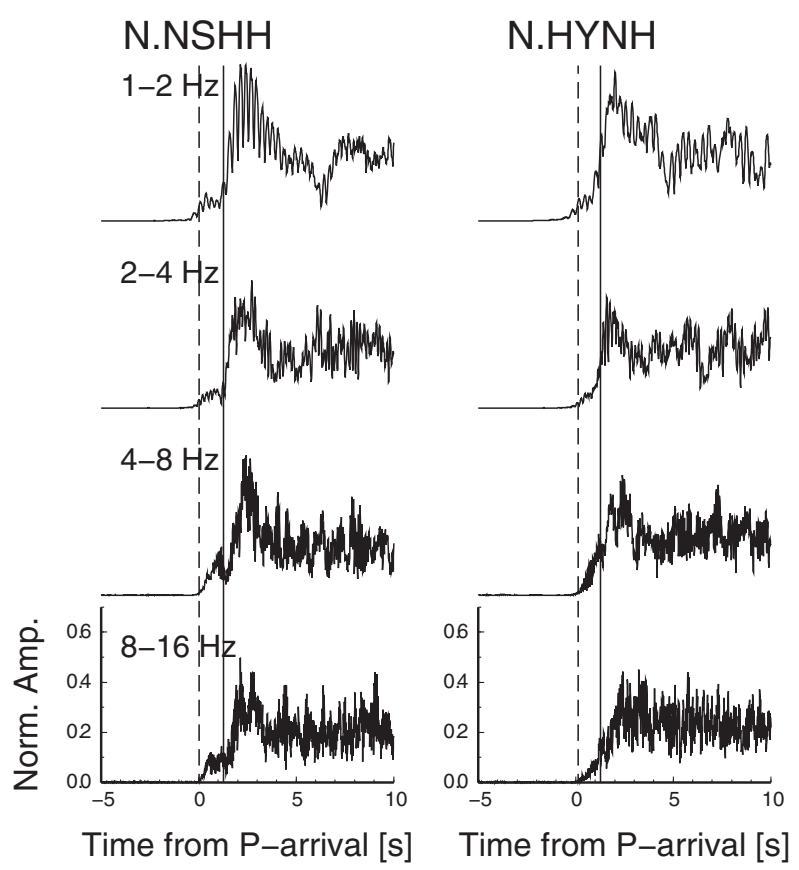

Figure 10 Simulated and observed RMS envelopes of the vertical component recorded at the N.NSHH and N.HYNH stations. (a) Simulation results of model A2 including small-scale velocity heterogeneities. (b) Observed stacked envelopes. N.NSHH and N.HYNH are located at distances of 111 and $155 \mathrm{~km}$, respectively. Each trace was normalized to its maximum amplitude. The dashed and solid lines in each trace are the onsets of the $P$ and trapped $P$ waves, respectively.

the Philippine Sea plate at depths beneath $40 \mathrm{~km}$ related with the overlying serpentinized fore-arc wedge mantle. Bostock et al. (2002) analyzed scattered teleseismic waves and also reported velocity change at similar depths beneath the Cascadia. Their works could not resolve the detailed velocity changes of the upper oceanic crust of oceanic plate but support our conclusions.

Based on thermodynamic forward modeling, Kuwatani et al. (2011) have showed that dehydration proceeds near the boundary between the greenschist and amphibolite facies, where chlorite is reacted out (e.g., Apted and Liou 1983), at depths of approximately $40 \mathrm{~km}$, under the pressure-temperature condition of the subducting Philippine Sea plate beneath southwestern Japan. They discussed that this metamorphic-dehydration reaction is expected to generate about $2 \mathrm{wt} \%$ of water and amphibolite rocks with $P$-wave velocities of approximately $7 \mathrm{~km} / \mathrm{s}$. Our seismological findings derived from the trapped $P$-wave analysis might be consistent with the results from these geochemical studies. However, the lowvelocity layer at the top of the Philippine Sea plate beneath the Kanto region was not strictly identified as either oceanic or arc crusts. There are lateral structural variations of the Philippine Sea plate around Izu-Bonin arc that is located at south of the Kanto region (e.g., Kodaira et al. 2007). Ohmi and Hurukawa (1996) also pointed out that the shallow crustal layer of the Philippine Sea Plate might be the crust of the subducting Izu-Bonin arc. This issue, including our interpretation of velocity increase in the low-velocity layer, is still open question and should be examined in the future.

In the southwestern Japan, the detailed structure of the Philippine Sea plate has been revealed by extensive seismic studies (e.g., Hirose et al. 2008a, b; Nakanishi et al. 2008; Kato et al. 2010, 2014; Nishizawa et al. 2011). Comparing characteristics of seismic wave propagation between the southwestern Japan and Kanto area examined in this study could reveal more precise structure and fluid distribution in the subducting oceanic crust of the Philippine Sea plate.

\section{Conclusions}

We analyzed the high-frequency ( 1 to $16 \mathrm{~Hz}$ ) trapped $P$ waves propagating along the oceanic crust of the Philippine Sea plate beneath the Kanto-Tokai region, Japan. The trapped $P$ waves were clearly observed at epicentral distances up to $150 \mathrm{~km}$ during earthquakes occurring in the oceanic crust of the Philippine Sea plate beneath the central Kanto region, showing pulse-like waveforms without significant dispersion and peak delay. These characteristics suggest that the trapped $P$ waves might be caused by a 
specific velocity structure of the subducting oceanic crust, which effectively traps high-frequency $P$-wave energy.

Using FDM simulations, we confirmed that the pulselike trapped $P$ waves were efficiently developed by trapping of seismic energy in a uniform velocity oceanic crust at the source depths. A uniform velocity oceanic crust at depths of 40 to $50 \mathrm{~km}$ could be formed by the velocity increase in the upper oceanic crust at 30 to $40 \mathrm{~km}$ depth due to metamorphic-dehydration reactions. Our results and further relating studies may constrain the detailed depth-dependent metamorphic-dehydration reactions in the subducting oceanic crust of the world.

\section{Competing interests}

The authors declare that they have no competing interests.

\section{Authors' contributions}

ST analyzed the observed waveforms, conducted numerical simulations, and drafted this manuscript. All authors carried out the theoretical considerations of rock physics and subduction processes, helped drafting, and read and approved the manuscript.

\section{Acknowledgements}

We would like to thank two anonymous reviewers and the editor, A. Nishizawa, for constructive comments that improved an earlier draft of this manuscript. We acknowledge the National Research Institute for Earth Science and Disaster Prevention, Japan (NIED) for providing the Hi-net waveform data and the CMT solutions from the F-net. The computations were conducted on the Earth Simulator at the Japan Agency for Marine-Earth Science and Technology (JAMSTEC) under the support of the joint research project 'Seismic wave propagation and strong ground motion in 3-D heterogeneous structure' conducted by the Earthquake Research Institute, the University of Tokyo, and the Center of Earth Information Science and Technology, JAMSTEC. ST is grateful for the financial support provided by the Grant-in-Aid for JSPS (the Japan Society for Promotion of Science; No. 24.5704) fellows. All figures in the present study were drawn using the Generic Mapping Tools software package.

\section{Author details}

${ }^{1}$ Department of Material System Science, Graduate School of Nanobioscience, Yokohama City University, 22-2, Seto, Kanazawa-ku, Yokohama 236-0027, Japan. ${ }^{2}$ Research and Development center for Earthquake and Tsunami, Japan Agency for Marine-Earth Science and Technology, 3173-25, Showa-machi, Kanazawa-ku, Yokohama 236-0001, Japan.

Received: 12 September 2014 Accepted: 26 February 2015 Published online: 18 March 2015

\section{References}

Abers G, Plank T, Hacker B (2003) The wet Nicaraguan slab. Geophys Res Lett 30:1098, doi:10.1029/2002GL015649

Apted MJ, Liou JG (1983) Phase relations among greenschist, epidoteamphibolite, and amphibolites in a basaltic system. Am J Sci 283:328-354

Bostock MG, Hyndman RD, Rondenay S, Peacock SM (2002) An inverted continental Moho and serpentinization of the forearc mantle. Nature 417:536-538, doi:10.1038/417536a

Fukao Y, Hori S, Ukawa M (1983) A seismological constraint on the depth of basalt-eclogite transition in a subducting oceanic crust. Nature 303:413-415, doi:10.1038/303413a0

Fukuyama E, Ishida M, Dreger DS, Kawai H (1998) Automated seismic moment tensor determination by using on-line broadband seismic waveforms. Zisin 51:149-156 (in Japanese with English abstract)

Furumura T, Chen L (2004) Large scale parallel simulation and visualization of 3-D seismic wavefield using Earth simulator. Comput Model Eng Sci 6:153-168, doi:10.3970/cmes/2004.006.153

Graves RW (1996) Simulating seismic wave propagation in 3D elastic media using staggered-grid finite differences. Bull Seismol Soc Am 86:1091-1106
Hacker BR, Peacock SM, Abers GA, Holloway SD (2003) Subduction factory 2. Are intermediate-depth earthquakes in subducting slab linked to metamorphic dehydration reactions? J Geophys Res 108:2030, doi:10.1029/2001JB001129

Hirose F, Nakajima J, Hasegawa A (2008a) Three-dimensional velocity structure and configuration of the Philippine Sea Slab beneath Kanto distinct, central Japan, estimated by double-difference tomography. Zisin 60:124-138 (in Japanese with English abstract)

Hirose F, Nakajima J, Hasegawa A (2008b) Three-dimensional seismic velocity structure and configuration of the Philippine Sea slab in southwestern Japan estimated by double-difference tomography. J Geophys Res 133:B09315, doi:10.1029/2007JB005274

Hori S (1990) Seismic waves guided by untransformed oceanic crust subducting into the mantle: case of the Kanto distinct, central Japan. Tectonophysics 176:355-376, doi:10.1016/0040-1951(90)90078-M

Hori S (2006) Seismic activity associated with the subducting motion of the Philippine Sea plate beneath the Kanto distinct, Japan. Tectonophysics 417:85-100, doi:10.1016/j.tecto.2005.08.027

Hori S, Inoue H, Fukao Y, Ukawa M (1985) Seismic detection of the untransformed 'basaltic' oceanic crust subducting into the mantle. Geophys J R Astron Soc 83:169-197, doi:10.1111/j.1365-246X.1985.tb05162.x

Iwamori H, Zhao D (2000) Melting and seismic structure beneath the northeast Japan Arc. Geophys Res Lett 27:425-428, doi:10.1029/1999GL010917

Kamiya S, Kobayashi Y (2000) Seismological evidence for the existence of serpentinized wedge mantle. Geophys Res Lett 27:819-822, doi:10.1029/ 1999GL011080

Kato A, lidaka T, Ikuta R, Yoshida Y, Katsumata K, Iwasaki T, Sakai S, Thurber C, Tsumura N, Yamaoka K, Watanabe T, Kunitomo T, Tamazaki F, Okubo M, Suzuki S, Hirata N (2010) Variation of fluid pressure within the subducting oceanic crust and slow earthquakes. Geophys Res Lett 37:L14310, doi:10.1029/2010GL043723

Kato A, Saiga A, Takeda T, Iwasaki T, Matsuzawa T (2014) Non-volcanic seismic swarm and fluid transportation driven by subduction of the Philippine Sea slab beneath the Kii Peninsula, Japan. Earth Planets Space 66:86, doi:10.1186/ 1880-5981-66-86

Kawakatsu H, Watada S (2007) Seismic evidence for deep-water transportation in the mantle. Science 316:1468, doi:10.1126/science.1140855

Kimura H, Kasahara K, Igarashi T, Hirata N (2006) Repeating earthquake activities associated with the Philippine Sea plate subduction in the Kanto district, central Japan: a new plate configuration revealed by interpolate aseismic slips. Tectonophysics 417:101-118, doi:10.1016/j.tecto.2005.06.013

Kimura H, Kasahara K, Takeda T (2009) Subduction process of the Philippine Sea plate off the Kanto district, central Japan, as revealed by plate structure and repeating earthquakes. Tectonophysics 472:18-27, doi:10.1016/j.tecto.2008. 05.012

Kirby S, Engdahl RE, Denlinger R (1996) Intermediate-depth intraslab earthquakes and arc volcanism as physical expressions of crustal and uppermost mantle metamorphism in subducting slabs. In: Bebout GE et al (eds) Subduction: top to bottom, vol 96, Geophysics monogram series. AGU, Washington DC, pp 195-214

Kodaira S, Sato T, Takahashi N, Ito A, Tamura Y, Tatsumi Y, Kaneda Y (2007) Seismological evidence for variable growth of crust along the Izu intraoceanic arc. J Geophys Res 112:B05104, doi:10.1029/2006JB004593

Koketsu K, Miyake H, Fujiwara H, Hashimoto T (2008) Progress towards a Japan integrated velocity structure model and long-period ground motion hazard map. In: Proceedings of the 14th World conference on earthquake engineering, 12-17 October 2008, Beijing

Kumar P, Kawakatsu H (2011) Imaging the seismic lithosphere-asthenosphere boundary of the oceanic plate. Geochem Geophys Geosyst 12:Q01006, doi:10.1029/2010GC003358

Kuwatani T, Okamoto A, Toriumi M (2011) Thermodynamic forward modeling of progressive dehydration reactions during subduction of oceanic crust under greenschist facies conditions. Earth Planet Sci Lett 307:9-18, doi:10.1016/j. epsl.2011.01.027

Levander AR (1988) Fourth-order finite-difference P-SV seismograms. Geophysics 53:1425-1436, doi:10.1190/1.1442422

Maeda T, Obara K, Furumura T, Saito T (2011) Interference of long-period seismic wavefield observed by the dense Hi-net array in Japan. J Geophys Res 116:B10303, doi:10.1029/2011JB008464

Magee EM, Zoback MD (1993) Evidence for a weak interpolate thrust fault along the northern Japan subduction zone and implications for the mechanics of thrust faulting and fluid expulsion. Geology 21:809-812, doi:10.1130/0091-7613(1993) 
Martin S, Rietbrock A (2006) Guided waves subduction zones: dependencies on slab geometry, receiver locations and earthquake sources. Geophys J Int 167:693-704, doi:10.1111/j.1365-246X.2006.02963

Matsubara M, Hayashi H, Obara K, Kasahara K (2005) Low-velocity oceanic crust at the top of the Philippine Sea and Pacific plates beneath the Kanto region, central Japan, imaged by seismic tomography. J Geophys Res 110:B12304, doi:10.1029/2005JB003673

Matsubara M, Obara K, Kasahara K (2008) Three-dimensional P- and S-wave velocity structures beneath the Japan Islands obtained by high-density seismic stations by seismic tomography. Tectonophysics 454:86-103, doi:10.1016/j.tecto.2008.04.016

Mavroeidis GP, Papageorgiou AS (2003) A mathematical representation of nearfield ground motions. Bull Seismol Soc Am 93:1099-1131, doi:10.1785/ 0120020100

Miyoshi T, Saito T, Shiomi K (2012) Waveguide effects within the Philippine Sea slab beneath southwest Japan inferred from guided SP converted waves. Geophys J Int 189:1075-1084, doi:10.1111/j.1365-246X.2012.05409.x

Nakajima J, Tsuji Y, Hasegawa A (2009) Seismic evidence for thermally-controlled dehydration reaction in subducting oceanic crust. Geophys Res Lett 36:L03303, doi:10.1029/2008GL0036865

Nakanishi A, Kodaira S, Miura S, Ito A, Sato T, Park JO, Kido Y, Kaneda Y (2008) Detailed structural image around splay-fault branching in the Nankai subduction zone: results from a high-density ocean bottom seismic survey. J Geophys Res 133:B03105, doi:10.1029/2007JB004974

Nishizawa A, Kaneda K, Oikawa M (2011) Backarc basin oceanic crust and uppermost mantle seismic velocity structure of the Shikoku Basin, south of Japan. Earth Planets Space 63:151-155, doi:10.5047/eps.2010.12.003

Ohmi S, Hurukawa N (1996) Detection of the subducting crust of oceanic plates beneath the Kanto district, Japan. Tectonophysics 261:249-276, doi:10.1016/ 0040-1951(95)00150-6

Okada Y, Kasahara K, Hori S, Obara K, Sekiguchi S, Fujiwara H, Yamamoto A (2004) Recent progress of seismic observation networks in Japan: Hi-net, F-net, K-NET and KiK-net. Earth Planets Space 56:xv-xxviii

Okamoto T, Takenaka H (2005) Fluid-solid boundary implementation in the velocity-stress finite-difference method. Zisin 57:355-364 (in Japanese with English abstract)

Sato H, Fehler M, Maeda T (2012) Seismic wave propagation and scattering in the heterogeneous earth structure, 2nd edn. Springer, New York

Seno T, Stein S, Gripp AE (1993) A model for the motion of the Philippine Sea plate consistent with NUVEL-1 and geophysical data. J Geophys Res 98:17941-17948, doi:10.1029/93JB00782

Shiina T, Nakajima J, Toyokuni G, Matsuzawa T (2014) Guided wave observations and evidence for the low-velocity subducting crust beneath Hokkaido, northern Japan. Earth Planets Space 66:69, doi:10.1186/1880-5981-66-69

Takahashi T, Sato H, Nishimura T, Obara K (2007) Strong inhomogeneity beneath Quaternary volcanoes revealed from the peak delay analysis of S-wave seismograms of microearthquakes in northeastern Japan. Geophys J Int 168:90-99, doi:10.1111/j.1365-246X.2006.03197.x

Takemura S, Yoshimoto K (2014) Strong seismic wave scattering in the lowvelocity anomaly associated with subduction of oceanic plate. Geophys J Int 197:1016-1032, doi:10.1093/gji/ggu031

Tatsumi Y (1989) Migration of fluid phases and genesis of basalt magmas in subduction zones. J Geophys Res 94:4697-4707, doi:10.1029/JB094iB04p04697

Tsuji Y, Nakajima J, Hasegawa A (2008) Tomographic evidence for hydrated oceanic crust of the Pacific slab beneath northeastern Japan: implications for water transportation in subduction zones. Geophys Res Lett 35:L14308, doi:10.1029/2008GL03446

Submit your manuscript to a SpringerOpen ${ }^{\circ}$ journal and benefit from:

- Convenient online submission

- Rigorous peer review

- Immediate publication on acceptance

- Open access: articles freely available online

- High visibility within the field

- Retaining the copyright to your article

Submit your next manuscript at $>$ springeropen.com 